\title{
Severity of Diverticulitis Does Not Influence Abdominal Complaints during Long-Term Follow-Up
}

\author{
Max Ditzel ${ }^{b, d}$ Sandra Vennix ${ }^{b}$ Anand G. Menon ${ }^{c}$ Paul C.M. Verbeek ${ }^{a}$ \\ Willem A. Bemelman ${ }^{b}$ Johan F. Lange ${ }^{c, d}$ \\ ${ }^{a}$ Department of Surgery, Flevohospital Almere, Almere, The Netherlands; ${ }^{b}$ Department of Surgery, Academic \\ Medical Center, Amsterdam, The Netherlands; ' Department of Surgery, Erasmus Medical Center, Havenziekenhuis, \\ Rotterdam, The Netherlands; ${ }^{\mathrm{d}}$ Department of Surgery, Erasmus Medical Center, Rotterdam, The Netherlands
}

\author{
Keywords \\ Diverticulitis · Long-term follow-up · Chronic abdominal \\ pain $\cdot$ Abdominal adhesions
}

\begin{abstract}
Background: Diverticulitis can lead to localized or generalized peritonitis and consequently induce abdominal adhesion formation. If adhesions would lead to abdominal complaints, it might be expected that these would be more prominent after operation for perforated diverticulitis with peritonitis than after elective sigmoid resection. Aims: The primary outcome of the study was the incidence of abdominal complaints in the long-term after acute and elective surgery for diverticulitis. Methods: During the period 2003 through 2009, 269 patients were operated for diverticular disease. Two hundred eight of them were invited to fill out a questionnaire composed of the gastrointestinal quality of life index and additional questions and finally 109 were suitable for analysis with a mean follow-up of 7.5 years. Results: Analysis did not reveal any significant differences in the incidence of abdominal complaints or other parameters. Conclusion: This retrospective study on patients after operation for diverticulitis shows that in the long term, the severity of
\end{abstract}

\begin{tabular}{ll}
\hline KARGER & ( 2018 The Author(s) Karger \\
& Published by S. Karger AG, Basel Open access \\
E-Mail karger@karger.com & This article is licensed under the Creative Commons Attribution- \\
www.karger.com/dsu & $\begin{array}{l}\text { NonCommercial-NoDerivatives 4.0 International License (CC BY- } \\
\text { NC-ND) (http://www.karger.com/Services/OpenAccessLicense). } \\
\text { Usage and distribution for commercial purposes as well as any dis- } \\
\text { tribution of modified material requires written permission. }\end{array}$
\end{tabular}

the abdominal complaints is influenced neither by the stage of the disease nor by the fact of whether it was performed in an acute or elective setting.

(C) 2018 The Author(s)

Published by S. Karger AG, Basel

\section{Introduction}

The role of intra-abdominal adhesions with regard to symptoms remains unclear [1-4]. As the diagnosis of infertility and ileus caused by adhesions is well established, especially pain and other chronic complaints can be related to adhesions less obviously. Diverticular disease is a common condition that has been a cause of increased hospital admission in recent years [5]. Although in $75 \%$ of the cases non-surgical management will be sufficient, in about one quarter, surgery should be considered. Elective surgery can be performed in cases of recurrent disease, stenosis, fistula formation, and the suggestion of malignancy, while acute operative management can be indicated due to local or generalized peritonitis (Hinchey III and IV) $[6,7]$. Especially the latter might induce abdominal adhesion formation possibly resulting in smallbowel obstruction, difficulties at reoperation, and infer- 
Table 1. Calculation of the score: most desirable option: 4. Points least desirable option: 0. Points GIQLI digestion sub-scale score: sum of the points

GIQLI questionnaire, questions digestion sub-scale score

questions

answer

During the past 2 weeks, how often have you had pain in the abdomen?

0. All of the time

During the past 2 weeks, how often have you had a feeling of fullness in the upper abdomen?

1. Most of the time

During the past 2 weeks, how often have you had bloating (sensation of too much gas in the abdomen)?

During the past 2 weeks, how often have you been troubled by excessive passage of gas through the anus?

During the past 2 weeks, how often have you been troubled by strong burping or belching?

2. Some of the time

3. Rarely

4. Never

During the past 2 weeks, how often have you been troubled by gurgling noises from the abdomen?

During the past 2 weeks, how often have you been troubled by fluid or food coming up into your mouth

(regurgitation)?

During the past 2 weeks, how often have you felt uncomfortable because of your slow speed of eating?

During the past 2 weeks, how often have you been troubled by constipation?

During the past 2 weeks, how often have you been troubled by heartburn?

tility $[8,9]$. Abdominal adhesions are also considered to be associated with chronic abdominal pain, although this remains widely under debate $[1,3,10]$. Provided that adhesions can induce chronic abdominal pain, one might expect more complaints after operation for diverticulitis with generalized peritonitis.

Recently it was shown that severe recurrence after successful nonoperative management of acute diverticulitis was low, and emergency surgery was rare [7, 11]. However, for those cases where operation is inevitable, the evidence is sparse concerning long-term effects. The aim of this study was to compare the severity of abdominal complaints following acute versus elective surgery for diverticular disease with a followup of 7.5 years.

\section{Methods}

This study is a retrospective analysis of all patients undergoing operation for diverticulitis from 2003 through 2010 in 2 academic hospitals (Erasmus Medical Center Rotterdam and Academic Medical Center Amsterdam) and 2 affiliated community hospitals (Flevohospital in Almere and Havenziekenhuis Rotterdam). Patients were identified using the hospital administration code for diverticulitis with surgical therapy. They were excluded from analyses if postoperative pathology reports showed malignancy instead of diverticulitis. The study design was analogous to an earlier follow-up report of our research group [2]. Data on demography, clinical presentation, histopathology, operative reports, long-term outcomes, and postoperative complications were reviewed. In those cases where medical files were incomplete, the patients were excluded. In 2014, all patients were invited to fill out a questionnaire by regular mail. All survival data and addresses were checked at the municipal offices and nonresponders (NR) were contacted again after 6 weeks.
The need for ethical review was waived by the Ethical Committees of the participating hospitals, as it is not required for this type of study in the Netherlands. Informed consent was obtained from all patients who completed the questionnaire.

\section{Definitions}

All patients were asked to confirm whether they experienced abdominal complaints during the previous 6 months. These complaints were further specified using the validated gastrointestinal quality of life index (GIQLI) questionnaire. The severity of diverticulitis was assessed according to the Hinchey classification [12] and based on the timing of the surgery. Acute surgery was defined as an operation within $24 \mathrm{~h}$ after admission. Laparoscopy included all laparoscopic procedures, including hand-assisted procedures. Conversion to open surgery was for the long-term results considered as open surgery. Postoperative bowel obstruction was defined as passage problems requiring placement of a nasogastric tube.

\section{Questionnaire}

The questionnaire was divided into 2 parts: part 1 consisted of general questions about re-interventions and abdominal complaints: part 2 consisted of the GIQLI, an established tool for assessing the quality of life concerning different gastro-intestinal diseases [13]. This questionnaire can be divided into 4 subscales measuring different aspects of the quality of life - physical well-being, mental well-being, digestion, and defecation as described by Nieveen Van Dijkum et al. [14]. Gastrointestinal symptoms are reflected by the digestion sub-score consisting of questions about pain and fullness in the abdomen, bloating, flatus, burping, abdominal noises, regurgitation, eating speed, constipation, and heartburn (Table 1). These symptoms are of most interest and therefore the digestion sub-scale was used for further analysis.

\section{Outcomes of the Study}

The primary outcome of the study was the incidence of abdominal complaints on the long-term effects after acute and elective surgery for diverticulitis. In addition, different Hinchey classification patterns, the influence of the operation technique (open vs. laparoscopic), presence of a (temporary) stoma, incisional hernia, reoperation, or small-bowel obstruction were investigated. 
Statistical Analysis

Categorical variables were represented as a number (percentage). Continuous variables were presented as mean (SD). Categorical variables were compared with the chi-square test, in the case of a count expected less than 5, a Fisher exact test was used; continuous variables were compared with the Student $t$ test. In those cases where more than 3 groups with continuous variables were compared, the one-way analysis of variance test was used. All analyses were conducted using SPSS version 22.0.0 (SPSS Inc., Chicago, IL, USA). A $p$ value $<0.05$ (2-sided) was considered statistically significant.

\section{Results}

During the period 2003 through 2009, 269 patients were operated for diverticular disease. Of this group, 61 (22.7\%) persons were excluded as they passed away (47), emigrated (2), or no correct contact records (12) were available. Therefore, 208 questionnaires were sent. Finally, 109 (52.4\%) of them (28 after acute operation, 81 after elective operation) were suitable for complete analysis as shown in Figure 1. Mean follow-up time from initial operation was 7.5 years and did not significantly vary between responders (R) and NR (R 7.3 years vs. NR 7.7 years, $p=0.112$ ). The $\mathrm{R}$ group was comparable with the NR group in terms of age, gender, operation technique, location of the diverticulitis, postoperative small-bowel obstruction and abscesses, timing of operation, Hinchey classification, and the number of reoperations (Table 2).

When asked about abdominal complaints during the previous 6 months, 48 patients mentioned no complaints at all, 37 were affected only during a small portion of the time, and 24 patients were afflicted by abdominal pain most or all of the time. Hinchey classification or timing of operation was not a risk factor, but this was further analyzed using the GIQLI. This analysis did not reveal any significant differences of the digestion subscale score for gender, operation technique, Hinchey classification, timing of operation, creation of a (temporary) stoma, reoperation, or bowel obstruction within 30 days as shown in Table 3. During follow-up, no significant differences between acute (A) and electively (E) operated patients were seen in hospital readmissions for abdominal complaints (A 32\% vs. E 31\%, $p=0.808$ ), incisional hernia (A $32 \%$ vs. E $20 \%, p=0.189$ ), or small-bowel obstruction (A $11 \%$ vs. E $5 \%, p=0.306$; Table 4 ).

In the total study population, patients with Hinchey III or IV were mostly operated in the acute setting (70 out of 74). In total, 16 patients ( 3 with Hinchey I or II vs. 13 with Hinchey III or IV) died within 30 days after the initial

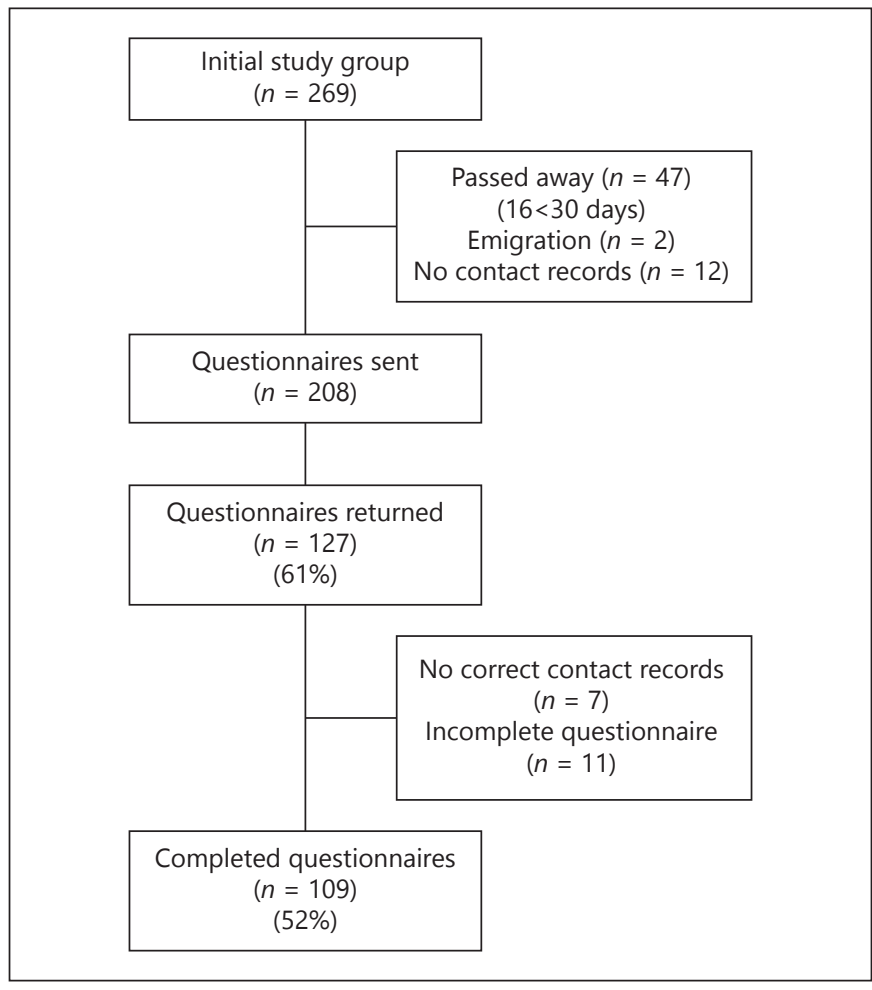

Fig. 1. Study profile.

operation. At the time of follow-up, 47 (mean age 71.1) patients had passed away and 39 (mean age 72.6 years) of them were urgently operated upon. In the R group, an open technique was significantly used more in the acute setting and these patients were significantly diagnosed more with Hinchey type III or IV (Table 5).

In the whole study population, $49(18 \%)$ patients were reoperated one or more times within 30 days of initial operation because of bleeding (4), anastomotic leakage (11), wound dehiscence (6), open abdomen treatment (3), deep wound infection (3), rinsing of the abdomen (8), replacing ileostomy (2), small-bowel obstruction (2), or for other reasons (10). Baseline characteristics are described in Table 2.

In the R group, an end-colostomy was created in 9 patients, a protective ileostomy in 32, and a terminal ileostomy in 8 patients. At the end of follow-up, the bowel continuity was restored in 33 out of 43 patients (77\%). No significant differences in the digestive subscale were found between the 43 patients with or the 66 without a stoma (Table 3). Additional analysis of the 33 patients in which the bowel continuity was restored did not reveal any differences as well (restored 32.5 vs. others 31.6; $p=$ $0.576)$. 
Table 2. $p$ value concerns differences between $\mathrm{R}$ and NR. Analysis of NR and R excludes 47 deceased patients

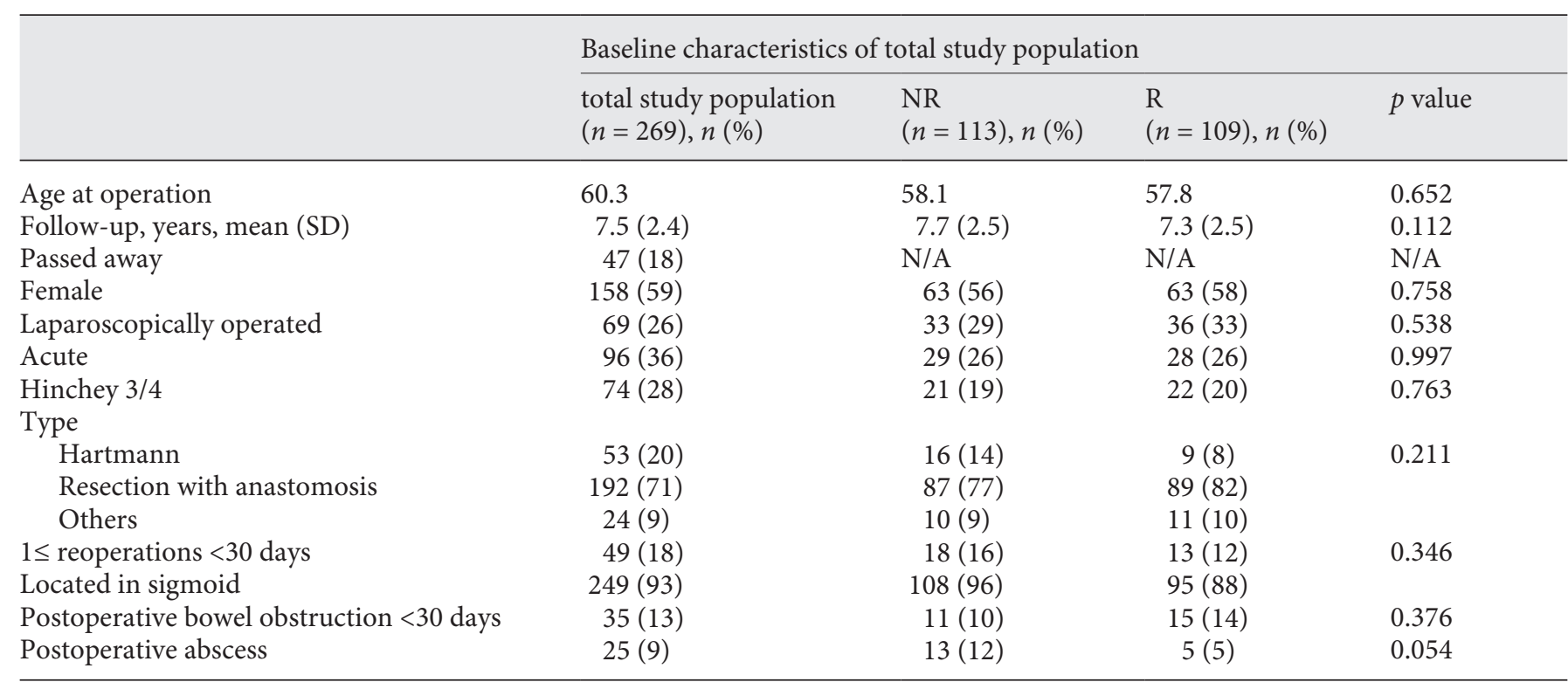

N/A, not applicable.

Table 3. GIQLI, digestion sub-scale score. A higher score equals good outcome

\begin{tabular}{|c|c|c|c|}
\hline & \multicolumn{3}{|c|}{$\begin{array}{l}\text { GIQLI questionnaire, results } \\
\text { digestion sub-scale score }\end{array}$} \\
\hline & $n=109$ & $\begin{array}{l}\text { mean digestive } \\
\text { subscore }\end{array}$ & $p$ value \\
\hline \multicolumn{3}{|l|}{ Gender } & 0.385 \\
\hline Male & 46 & 32.5 & \\
\hline Female & 63 & 31.5 & \\
\hline \multicolumn{3}{|l|}{ Technique } & 0.078 \\
\hline Laparoscopic & 36 & 30.1 & \\
\hline Open/converted & 73 & 32.8 & \\
\hline \multicolumn{3}{|l|}{ Timing } & 0.931 \\
\hline Elective & 81 & 32.0 & \\
\hline Acute & 28 & 31.6 & \\
\hline \multicolumn{3}{|l|}{ Hinchey } & 0.642 \\
\hline $1-2$ & 87 & 31.7 & \\
\hline $3-4$ & 21 & 32.9 & \\
\hline \multicolumn{3}{|l|}{ Technique } & 0.962 \\
\hline Hartmann & 9 & 31.8 & \\
\hline Resection with anastomosis & 89 & 32.3 & \\
\hline Others & 11 & 32.4 & \\
\hline \multicolumn{3}{|l|}{$1 \leq$ reoperations $<30$ days } & 0.173 \\
\hline Yes & 13 & 29.5 & \\
\hline No & 96 & 32.3 & \\
\hline \multicolumn{3}{|c|}{ Postoperative bowel obstruction $<30$ days } & 0.575 \\
\hline Yes & 15 & 32.5 & \\
\hline No & 94 & 31.8 & \\
\hline \multicolumn{3}{|l|}{ Stoma } & 0.443 \\
\hline Yes & 43 & 32.7 & \\
\hline No & 66 & 31.4 & \\
\hline
\end{tabular}

\section{Discussion}

This retrospective study on the long-term complications after acute and elective operation in case of diverticulitis shows that the severity of the abdominal complaints is influenced neither by the stage of the disease nor by the fact of whether it was performed in an acute or elective setting.

Postsurgical abdominal adhesions contribute to an increased risk of small-bowel obstruction, difficulties at the time of reoperation, and infertility in women [15-17]. Every abdominal operation can induce adhesion formation, although in general it has been shown that laparotomy results in more adhesion formation than laparoscopy [18-21]. Another cause for the formation of adhesions is the presence of localized or generalized peritonitis [22, 23]. In this respect, it has been shown that after perforated appendicitis, the incidence of adhesionrelated small-bowel obstruction significantly increases compared to that of non-perforated appendicitis [24, 25].

Abdominal adhesions are also associated with chronic abdominal pain; nevertheless, this relation has been subject of discussion for decades. It has been suggested that traction of adhesions on the peritoneum and viscera, nerve fibers in adhesions itself, or changes in the nervous system might contribute to chronic abdominal pain caused by adhesions when other organic 
Table 4. Events during follow-up. $p$ value concerns differences between $A$ and $E$ operated patients in the R group

\begin{tabular}{|c|c|c|c|c|}
\hline & \multicolumn{4}{|c|}{ Events during follow-up } \\
\hline & $\begin{array}{l}\mathrm{R} \\
(n=109), n(\%)\end{array}$ & $\begin{array}{l}\mathrm{A} \\
(n=28), n(\%)\end{array}$ & $\begin{array}{l}\mathrm{E} \\
(n=81), n(\%)\end{array}$ & $p$ value \\
\hline Readmission for abdominal complaints & $34(31)$ & $9(32)$ & $25(31)$ & 0.808 \\
\hline Small-bowel obstruction nonoperative & $7(6)$ & $3(11)$ & $4(5)$ & 0.306 \\
\hline Small-bowel obstruction operative & $5(5)$ & $1(4)$ & $4(5)$ & 0.837 \\
\hline
\end{tabular}

Table 5. Baseline characteristics. $p$ value concerns differences between A and E operated patients in the R group

\begin{tabular}{|c|c|c|c|c|}
\hline & \multicolumn{4}{|c|}{ Baseline characteristics; A vs. E } \\
\hline Age at operation & 57.8 & 57.7 & 57.8 & 0.965 \\
\hline Follow-up, years, mean (SD) & $7.3(2.5)$ & $7.5(2.2)$ & $7.2(2.5)$ & 0.594 \\
\hline Female & $63(58)$ & $17(61)$ & $46(57)$ & 0.717 \\
\hline \multicolumn{5}{|l|}{ Type } \\
\hline Hartmann & $9(8)$ & $7(25)$ & $2(3)$ & $<0.001$ \\
\hline Resection with anastomosis & $89(82)$ & $15(54)$ & $74(91)$ & \\
\hline Others & $11(10)$ & $6(21)$ & $5(6)$ & \\
\hline $1 \leq$ reoperations $<30$ days & $13(12)$ & $4(14)$ & $9(11)$ & 0.655 \\
\hline
\end{tabular}

and functional diseases are excluded $[1,4]$. However, other studies and this data do not support that relationship $[2,3]$.

Provided that abdominal adhesions can cause chronic abdominal pain, one might expect more complaints after open surgery and/or operation for Hinchey types III and IV. In this study, almost all operations in the acute setting were performed using the open technique (95 out of 96) and when patients were diagnosed with Hinchey classification III or IV, they were directly operated on (70 out 74). Therefore, we hypothesized that patients operated in the acute setting might have more abdominal complaints after long-term follow-up. However, neither the timing of the operation nor the Hinchey classification proved to be a risk factor for abdominal complaints in the long term. Additionally, no significant differences were seen in terms of gender, operation technique, reoperation rate within 30 days, or the presence of a (temporary) stoma. It is also possible that the impact of other abdominal operations during follow-up influenced our data. However, the number of operations did not significantly differ between the 2 groups suggesting that a potential effect of these operations was the same in both groups (Table 4).

Although the Hansen-Stock classification might have been more appropriate to apply, in the hospitals that were involved in this study, the Hinchey classification for severity of diverticulitis was used, as it is still generally applied in most studies [26-29]. Even more promising seems to be CT in combination with clinical parameters as recently stated by Bolkenstein et al. [26].

Despite the fact that this study did not find any differences between the 2 groups concerning abdominal complaints, a significant number of patients suffered from them. One can only hypothesize about the cause of 
these complaints. In recent years, an evident correlation between the development of IBS and one or more episodes of diverticulitis has been shown, in conservatively as well as in operatively treated patients [30-32]. The exact pathophysiological mechanism still remains unclear, but one hypothesis includes a strong correlation between the inflammatory reaction induced by diverticulitis and the development of IBS, analogous to the postinflammatory model of postinflammatory-IBS [30, 33]. Since all patients in the present study were diagnosed with diverticular disease, the number of patients possibly with IBS should be randomly divided between the different groups and therefore not interfere with our results.

To the knowledge of the authors, the long-term effect on chronic abdominal complaints of acute versus elective surgery for diverticular disease has never been investigated. In recent years, it has become increasingly evident that individual patient factors are of significant importance when deciding whether colonic resection for diverticular disease should be performed or not. Different authors have shown that in carefully selected patients, elective surgery improves the quality of life compared to conservative therapy, although obviously the risk of complications should always be considered [34-36]. Recent results of the direct-direct trial confirm this, showing that elective sigmoidectomy, despite its inherent risk of complications, results in better quality of life than conservative management in patients with recurrent and persisting abdominal complaints after an episode of diverticulitis [28].

If elective surgery is indicated, guidelines agree that laparoscopic surgery is preferred in experienced hands because of lower morbidity and faster recovery $[37,38]$. In those cases where acute surgery is inevitable, evidence for a safe laparoscopic approach is weak, and similar to our study, an open approach is most commonly undertaken [37]. In the last decade, laparoscopic peritoneal lavage has been investigated as an alternative to sigmoidectomy in patients with purulent peritonitis owing to perforated diverticulitis. However, recent randomized trials demonstrated that peritoneal lavage is not superior to sigmoidectomy [27, 29]. As our study period ended in 2010, just before increasing the popularity of laparoscopic lavage in the Netherlands, no lavage was performed in our study. However, forthcoming data of 2 more trials on perforated diverticulitis might eventually change the way perforated diverticulitis will be treated [39-41]. It should be interesting to see what the effect will be on chronic abdominal com- plaints after long-term follow-up of laparoscopic lavage.

In the present study, 109 (52\%) questionnaires were suitable for complete analysis. This is equivalent to other retrospective quality-of-life studies reporting followup percentages between 37 and $52 \%$ after 2.5 to 7 years of follow-up [2, 42-44]. Baseline characteristics did not significantly differ between $\mathrm{R}$ and NR suggesting that the $\mathrm{R}$ group reflects the whole study population. However, comparable to all retrospective studies, our data should be interpreted carefully because of selection bias. Additionally, the limited power of $28 \mathrm{R}$ in the acute group should be taken into account. As mentioned above, $83 \%$ (39 out of 47 ) of the deceased patients were operated in the acute setting, relatively reducing the availability of patients for follow-up in this group. We can only speculate about the reason for the difference between the R/NR and total study population, but it is well known that age and general condition are important factors determining a successful outcome of surgery. The mean age of the deceased patients operated in the acute setting was 72.6 years. This is significantly older than the R/NR group (Table 2) and therefore a reasonable explanation for the larger number of deceased patients.

The treatment of diverticulitis continues to evolve toward an approach that is more conservative and minimally invasive [45]. However, when acute surgery is inevitable, collected data enable surgeons to inform patients that in the long run the amount of chronic abdominal complaints after acute operation will be comparable to patients who were electively operated on. Finally, as the presence of peritonitis in this study did not significantly relate to the occurrence of chronic abdominal complaints, it is concluded that adhesions play a minor role with regard to abdominal symptoms in the long term.

\section{Acknowledgments}

We would like to thank L. Leijsen, MD and D.P.V. Lambrichts, $\mathrm{MD}$ for their significant contribution in the collection of data.

\section{Disclosure Statements}

The authors declare that they have no conflicts of interest to disclose.
Ditzel/Vennix/Menon/Verbeek/ Bemelman/Lange 


\section{References}

1 Demco L: Pain mapping of adhesions. J Am $>15$ Menzies D: Peritoneal adhesions. Incidence, Assoc Gynecol Laparosc 2004;11:181-183.

$\checkmark 2$ Ditzel M, van Ginhoven TM, van der Wal JB, Hop W, Coene PP, Lange JF, van der Harst E: What patients and surgeons should know about the consequences of appendectomy for acute appendicitis after long-term follow-up: factors influencing the incidence of chronic abdominal complaints. J Gastrointest Surg 2013;17:1471-1476.

3 Swank DJ, Swank-Bordewijk SC, Hop WC, van Erp WF, Janssen IM, Bonjer HJ, Jeekel J: Laparoscopic adhesiolysis in patients with chronic abdominal pain: a blinded randomised controlled multi-centre trial. Lancet 2003;361:1247-1251.

4 van der Wal JBC: Chronic abdominal pain: the role of adhesions and benefit of laparoscopic adhesionlysis. Gyn Surg 2006;3:168174.

-5 Etzioni DA, Cannom RR, Ault GT, Beart RW Jr, Kaiser AM: Diverticulitis in California from 1995 to 2006: increased rates of treatment for younger patients. Am Surg 2009;75: 981-985.

6 Collins D, Winter DC: Elective resection for diverticular disease: an evidence-based review. World J Surg 2008;32:2429-2433.

7 Janes S, Meagher A, Frizelle FA: Elective surgery after acute diverticulitis. Br J Surg 2005; 92:133-142.

8 ten Broek RP, Issa Y, van Santbrink EJ, Bouvy ND, Kruitwagen RF, Jeekel J, Bakkum EA, Rovers MM, van Goor H: Burden of adhesions in abdominal and pelvic surgery: systematic review and met-analysis. BMJ 2013; 347:f5588.

-9 ten Broek RP, Strik C, Issa Y, Bleichrodt RP, van Goor H: Adhesiolysis-related morbidity in abdominal surgery. Ann Surg 2013;258: 98-106.

10 Sulaiman H, Gabella G, Davis MSc C, Mutsaers SE, Boulos P, Laurent GJ, Herrick SE: Presence and distribution of sensory nerve fibers in human peritoneal adhesions. Ann Surg 2001;234:256-261.

11 Trenti L, Kreisler E, Galvez A, Golda T, Frago $\mathrm{R}$, Biondo S: Long-term evolution of acute colonic diverticulitis after successful medical treatment. World J Surg 2015;39:266-274.

12 Hinchey EJ, Schaal PG, Richards GK: Treatment of perforated diverticular disease of the colon. Adv Surg 1978;12:85-109.

$\checkmark 13$ Eypasch E, Williams JI, Wood-Dauphinee S, Ure BM, Schmülling C, Neugebauer E, Troidl H: Gastrointestinal quality of life index: development, validation and application of a new instrument. Br J Surg 1995;82: 216-222.

-14 Nieveen Van Dijkum EJ, Terwee CB, Oosterveld P, Van Der Meulen JH, Gouma DJ, De Haes JC: Validation of the gastrointestinal quality of life index for patients with potentially operable periampullary carcinoma. Br J Surg 2000;87:110-115. cause, and prevention. Surg Annu 1992;24(pt 1):27-45.

16 Menzies D, Ellis H: Ellis, Intestinal obstruction from adhesions - how big is the problem? Ann R Coll Surg Engl 1990;72:60-63.

17 Van Der Krabben AA, Dijkstra FR, Nieuwenhuijzen M, Reijnen MM, Schaapveld M, Van Goor H: Morbidity and mortality of inadvertent enterotomy during adhesiotomy. $\mathrm{Br}$ J Surg 2000;87:467-471.

18 Gamal EM, Metzger P, Szabó G, Bráth E, Petõ K, Oláh A, Kiss J, Furka I, Mikó I: The influence of intraoperative complications on adhesion formation during laparoscopic and conventional cholecystectomy in an animal model. Surg Endosc 2001;15:873-877.

19 Di Saverio S, Coccolini F, Galati M, Smerieri N Biffl WL, Ansaloni L, Tugnoli G, Velmahos GC, Sartelli M, Bendinelli C, Fraga GP, Kelly MD, Moore FA, Mandalà V, Mandalà S, Masetti $\mathrm{M}$, Jovine $\mathrm{E}$, Pinna $\mathrm{AD}$, Peitzman $\mathrm{AB}$, Leppaniemi A, Sugarbaker PH, Goor HV, Moore EE, Jeekel J, Catena F: Bologna guidelines for diagnosis and management of adhesive small bowel obstruction (ASBO): 2013 update of the evidence-based guidelines from the world society of emergency surgery ASBO working group. World J Emerg Surg 2013;8:42.

20 Dowson HM, Bong JJ, Lovell DP, Worthington TR, Karanjia ND, Rockall TA: Reduced adhesion formation following laparoscopic versus open colorectal surgery. Br J Surg 2008; 95:909-914.

21 Klaristenfeld DD, McLemore EC, Li BH, Abbass MA, Abbas MA: Significant reduction in the incidence of small bowel obstruction and ventral hernia after laparoscopic compared to open segmental colorectal resection. Langenbecks Arch Surg 2015;400:505-512.

22 Deerenberg EB, Mulder IM, Ditzel M, Slieker JC, Bemelman WA, Jeekel J, Lange JF: Polyvinyl alcohol hydrogel decreases formation of adhesions in a rat model of peritonitis. Surg Infect (Larchmt) 2012;13:321-325.

23 van Goor H, Bom VJ, van der Meer J, Sluiter WJ, Bleichrodt RP: Coagulation and fibrinolytic responses of human peritoneal fluid and plasma to bacterial peritonitis. Br J Surg 1996; 83:1133-1135.

24 Andersson RE: Small bowel obstruction after 1391.

25 Leung TT, Dixon E, Gill M, Mador BD, Moulton KM, Kaplan GG, MacLean AR: Bowel obstruction following appendectomy: what is the true incidence? Ann Surg 2009; 250:51-53.

26 Bolkenstein HE, van de Wall BJM, Consten ECJ, Broeders IAMJ, Draaisma WA: Risk factors for complicated diverticulitis: systematic review and meta-analysis. Int J Colorectal Dis 2017;32:1375-1383.

-27 Angenete E, Thornell A, Burcharth J, Pommergaard HC, Skullman S, Bisgaard T, Jess appendicectomy. Br J Surg 2001;88:1387-
P, Läckberg Z, Matthiessen P, Heath J, Rosenberg J, Haglind E: Laparoscopic lavage is feasible and safe for the treatment of perforated diverticulitis with purulent peritonitis: the first results from the randomized controlled trial DILALA. Ann Surg 2016; 263:117-122.

28 van de Wall BJM, Stam MAW, Draaisma WA, Stellato R, Bemelman WA, Boermeester MA, Broeders IAMJ, Belgers EJ, Toorenvliet BR, Prins HA, Consten ECJ; DIRECT Trial Collaborators: Surgery versus conservative management for recurrent and ongoing leftsided diverticulitis (DIRECT trial): an openlabel, multicentre, randomised controlled trial. Lancet Gastroenterol Hepatol 2017;2: 13-22.

29 Vennix S, Musters GD, Mulder IM, Swank HA, Consten EC, Belgers EH, van Geloven AA, Gerhards MF, Govaert MJ, van Grevenstein WM, Hoofwijk AG, Kruyt PM, Nienhuijs SW, Boermeester MA, Vermeulen J, van Dieren S, Lange JF, Bemelman WA; Ladies Trial Colloborators: Laparoscopic peritoneal lavage or sigmoidectomy for perforated diverticulitis with purulent peritonitis: a multicentre, parallel-group, randomised, open-label trial. Lancet 2015;386:1269-1277.

30 Cohen E, Fuller G, Bolus R, Modi R, Vu M, Shahedi K, Shah R, Atia M, Kurzbard N, Sheen V, Agarwal N, Kaneshiro M, Yen L, Hodgkins P, Erder MH, Spiegel B: Increased risk for irritable bowel syndrome after acute diverticulitis. Clin Gastroenterol Hepatol 2013;11:1614-1619.

- 31 Jung HK, Choung RS, Locke GR 3rd, Schleck CD, Zinsmeister AR, Talley NJ: Diarrhea-predominant irritable bowel syndrome is associated with diverticular disease: a populationbased study. Am J Gastroenterol 2010;105: 652-661.

32 Spiller R: Editorial: new thoughts on the association between diverticulosis and irritable bowel syndrome. Am J Gastroenterol 2014; 109:1906-1908.

33 Spiller R, Campbell E: Post-infectious irritable bowel syndrome. Curr Opin Gastroenterol 2006;22:13-17.

-34 Forgione A, Leroy J, Cahill RA, Bailey C, Simone M, Mutter D, Marescaux J: Prospective evaluation of functional outcome after laparoscopic sigmoid colectomy. Ann Surg 2009; 249:218-224.

35 van de Wall BJ, Draaisma WA, van Iersel JJ, Consten EC, Wiezer MJ, Broeders IA: Elective resection for ongoing diverticular disease significantly improves quality of life. Dig Surg 2013;30:190-197.

36 Andeweg CS, Berg R, Staal JB, ten Broek RP, van Goor H: Patient-reported outcomes after conservative or surgical management of recurrent and chronic complaints of diverticulitis: systematic review and meta-analysis. Clin Gastroenterol Hepatol 2016;14:183190. 
37 Vennix S, Morton DG, Hahnloser D, Lange JF, Bemelman WA; Research Committee of the European Society of Coloproctocology: Systematic review of evidence and consensus on diverticulitis: an analysis of national and international guidelines. Colorectal Dis 2014; 16:866-878.

38 Gervaz P, Inan I, Perneger T, Schiffer E, Morel $\mathrm{P}$ : A prospective, randomized, single-blind comparison of laparoscopic versus open sigmoid colectomy for diverticulitis. Ann Surg 2010;252:3-8.

39 Thornell A, Angenete E, Gonzales E, Heath J, Jess P, Lackberg Z, Ovesen H, Rosenberg J, Skullman S, Haglind E, Scandinavian S; Surgical Outcomes Research Group: Treatment of acute diverticulitis laparoscopic lavage vs. resection (DILALA): study protocol for a randomised controlled trial. Trials 2011;12:186.

40 Winter DC, Hogan AM, Ryan K: LapLAND laparoscopic lavage for acute non-faeculant diverticulitis, 2009. https://clinicaltrials.gov/ ct2/show/NCT01019239.

41 Øresland T, Schultz JK, Yaqub S, Rashidi M, Nilsen FR; Scandinavian Diverticulitis Trial SCANDIV: A randomized prospective multicenter trial, 2010. www.scandiv.com/scandivprotokoll-181015.pdf.

2 Kapischke M, Friedrich F, Hedderich J, Schulz T, Caliebe A: Laparoscopic versus open appendectomy - quality of life 7 years after surgery. Langenbecks Arch Surg 2011;396:69-75.
43 Sokolovic E, Buchmann P, Schlomowitsch F, Szucs TD: Comparison of resource utilization and long-term quality-of-life outcomes between laparoscopic and conventional colorectal surgery. Surg Endosc 2004;18: 1663-1667.

-44 van Ramshorst GH, Eker HH, Hop WC, Jeekel J, Lange JF: Impact of incisional hernia on health-related quality of life and body image: a prospective cohort study. Am J Surg 2012;204:144-150.

45 McDermott FD, Collins D, Heeney A, Winter DC: Minimally invasive and surgical management strategies tailored to the severity of acute diverticulitis. Br J Surg 2014;101:e90e99. 